\title{
A quantitative analysis of the behaviour of the Chinstrap penguin Pygoscelis antarctica and Macaroni penguin Eudyptes chrysolophus on Bouvetøya during the late incubation and early nestling periods*
}

\author{
SVEIN HAFTORN
}

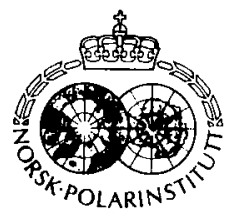

Haftorn, S. 1986: A quantitative analysis of the behaviour of the Chinstrap penguin Pygoscelis antarctica and Macaroni penguin Eudyptes chrysolophus on Bouvetøya during the late incubation and early nestling periods. Polar Research 4 n.s., 33-45.

The division of labour between the sexes, and their respective behaviour, were studied by means of timelapse photography during the incubation and brooding periods.

Chinstrap penguin. Both mates were equally attentive in incubating the eggs and brooding the smalt chicks. During late incubation the mean duration of a shift was $35 \mathrm{~h}$. This decreased to $14-15 \mathrm{~h}$ during the initial nestling period. Most reliefs took place around noon or in the evening/night, indicating a basic brooding shift of $12 \mathrm{~h}$. During the incubation and hatching periods the mate was absent (presumably at sea) for $29 \mathrm{~h}$ at a time, on average. The mean duration of absence decreased to $12-13 \mathrm{~h}$ during the early nestling stage, indicating that the adults had been feeding in nearby waters. Six adults with stomach contents had fed exclusively on krill Euphausia superba. During the incubation period the proportion of time spent prone averaged $92 \%$ of the total time spent on the nest, for both sexes, but. during the hatching and initial nestling periods, this decreased rapidly in relation to the time spent upright, probably because progressively less heat transfer from the brood patch was required.

Macaroni penguin. In the ten days just before the eggs were hatched the males at four nests were responsible for $82-100 \%$ of total incubation. Presence or absence of the females at the nests during this stage varied greatly. At one nest the female was not observed at all. At another she stayed by the nest during the entire survey period, but relieved the incubating male for only $5 \%$ of the time. During incubation the males adopted an upright posture far more often than the females, but even the latter incubated significantly more frequently upright than the Chinstrap penguin. This specific difference may be related to the fact that the Macaroni penguins had only a single egg. whereas the Chinstraps had two. The prone posture better enables the nest contents to be properly covered.

Both species. During incubation, both the male and female birds assumed a resting or sleeping posture for more than $90 \%$ of their time on the nest. Egg-shifting, rotation on the nest, and preening together accounted for about $2-3 \%$ of their time. Time spent in agonistic and territorial behaviour. unusually aroused by the presence of other penguins passing by, accounted for $0.9 \%$ of the time in the Chinstrap. but for only $0.1 \%$ in the Macaroni penguin. Ecstatic displays were sporadically observed in the Chinstrap by both sexes. Mean egg temperature during incubation, measured close to the top of the egg, was $37.4^{\circ} \mathrm{C}$ for both specics.

Svein Haftorn. University of Trondheim, The Museum, Erling Skakkesgt. 47A, N-7000 Trondheim, Norway: December 1984 (revised November 1985).

On the remote Bouvetøya island $\left(54^{\circ} 25^{\prime} \mathrm{S}\right.$, $3^{\circ} 21^{\prime} \mathrm{E}$ ) in the South Atlantic Ocean, just south of the Antarctic convergence, three species of penguins breed in colonies, the major ones being those of the Macaroni penguin Eudyptes chrysolophus and the Chinstrap penguin Pygoscelis antarctica. The third species, the Adelie penguin $P$. adeliae, breeds in small numbers only (Haftorn et al. 1981).

* Publication No. 72 of the Norwegian Antarctic Research Expeditions (1978-79).
As a member of the Norwegian Antarctic Expedition, I spent 12 days on Bouvetøya in 1978-79, from 24 December to 4 January. The main object was to make a census of the penguin colonies and record the bird fauna in general. In addition, I collected as much information about the behaviour and breeding biology of the penguins as our short stay allowed. To obtain data on the daily routines of the breeding population, records of a small part of the penguin colony at Nyrøysa, containing several breeding pairs of Macaroni and Chinstrap penguins, were made by time-lapse photography. 
Most of the Chinstrap clutches, which usually consisted of two eggs, were hatched during the survey period, indicating a high degree of synchrony in egg-laying within the colony. With an incubating time of 31-40 days (see Conroy et al. 1975a; Lishman 1985) this means that most eggs were laid in the period 10-25 November.

On our arrival, all the Macaroni nests investigated contained only one egg. No nests containing young were observed at that time. The many eggs found in the mud between the nests indicated that the clutches probably consisted of two eggs originally, one of which had been lost earlier. It is well known that many crested penguins lose one egg before hatching, perhaps as a result of the highly-developed aggression of the males shown both to their neighbours and to other penguins passing by (Warham 1975). On average, the eggs of the Macaroni penguin were hatched a few days later than those of the Chinstrap, but by 29 December hatching of the former was well under way.

The data presented here thus cover the last days of the incubation period, the hatching period, and the first days of the nestling period. In addition, information is provided about egg temperatures during the incubation.

\section{Material and methods}

From aerial photographs taken on 30 December 1978 , the penguin colony at Nyrøysa contained 14,826 individuals, $55.5 \%$ of which were estimated to be Chinstrap, $44.1 \%$ Macaroni, and 0.4\% Adelie penguins (Haftorn et al. 1981).

The group of penguins selected for time-lapse photography nested on slightly sloping ground within the colony (Fig. 1).

Marking.- To identify the individuals, the breast of one member of each of ten Chinstrap and ten Macaroni pairs was stained yellow with picric acid, after being caught at the nest site at the start of the survey. The sexes of five pairs of each species which were nesting in front of the camera were determined at the close of the survey, by autopsy of the particular bird which was then sitting on the nest. The sexes of the individual members of the other pairs remained unknown.

Time-lapse photography. - A Super 8 movie-camera, suitably modified for time-lapse photography was used. The birds were photographed at 1minute intervals, continuously from $1325 \mathrm{hrs}$ on 25 December to $1200 \mathrm{hrs}$ on 3 January, with the

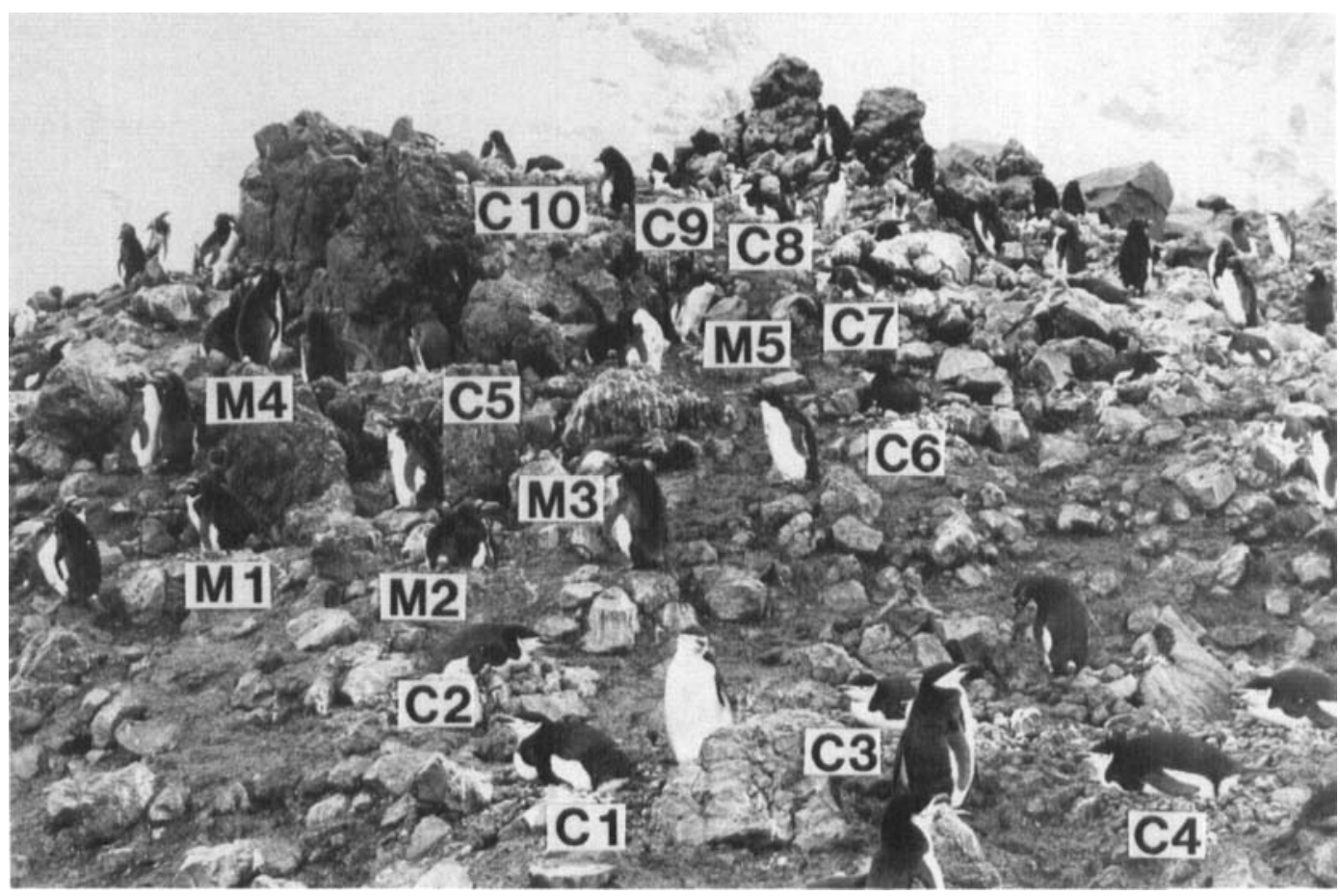

Fig. 1. The part of the penguin colony at Nyrøysa surveyed by time-lapse photography from 25 December 1978 to 3 January 1979. $C$ and $M=$ nests of the Chinstrap and Macaroni penguins, respectively. 
exception of the night-time periods when the light conditions were too poor for the sensitivity of the film used (Kodachrome 25ASA). Thus no records of the birds are available from about 2100$2200 \mathrm{hrs}$ in the evening to about $0500 \mathrm{hrs}$ the following morning.

To supplement the photographic record I made a note of the breast colour of the attentive birds several times each day, and also checked the contents of the nests from time to time.

Egg temperature.- The incubation temperature was recorded in one nest of each species by inserting a thermistor into an infertile penguin egg ( $T$ egg). The T-egg was kept in place by stones being placed over the probe wire, but in such a way that the incubating bird was still able to partially turn it. During the temperature recordings the thermistor was usually situated near the top of the egg, i.e. approximately at the site of the blastoderm. The T-egg, which was accepted straight away by the attentive birds, replaced one of the two eggs in the Chinstrap nest and the single egg in the Macaroni nest.

The temperature of the T-egg was monitored continuously for several hours using a Grant thermistor recorder. The same T-egg was used for both species.

Weather conditions. - During the survey the air temperature fluctuated around zero $\left(-1^{\circ}\right.$ to $\left.4^{\circ} \mathrm{C}\right)$. Snow covered the ground on three mornings, but melted during the day. The snow also temporarily blanketed the incubating penguins. Wind strengths were moderate, except on two occasions: on 28 December there was a strong NW wind with snow, and on 2 January a NW gale blew up, after a wet morning.

Data analysis.- The time-lapse films were analysed, frame by frame, using an Erno EM1801 Super 8 projector. Largely following Derksen (1977), I tried to divide the observed events into eight different categories: (1) resting or sleeping, (2) agonistic behaviour and territorial defence, (3) nest-building, (4) preening, (5) sexual displays (mainly mutual and ecstatic displays), (6) rotations (movement by the nest-sitter in either direction), (7) egg-shifting or contacting the young with the bill (including feeding them), (8) nest relief. It was also noted whether the bird was in a prone or upright position.

The attitudes of the birds right in front of the camera could easily be recognized from the timelapse films (the four Chinstrap nests, Nos. 1-4 on Fig. 1), but accuracy declined rapidly with distance from the camera. Nevertheless, fairly good records were obtained of the three pairs of Macaroni penguins nesting next to the abovementioned Chinstraps. Only fragmentary observations of those nesting further away from the camera were available, however, frequently because the bird under observation was hidden by its partner, or by other penguins sitting in front of it.

Statistics.- These are presented throughout as mean \pm SD.

\section{Results}

\section{The Chinstrap penguin}

Fig. 2 shows the course of the daily routines, with spells of incubation or brooding, together with the stage of breeding development, for five pairs of known sex and for a further five pairs one of the partners of which was dye-marked but whose sex remained unknown. In two of the nests, hatching was already complete by the start of the survey (Nest No. 6 with one newly-hatched young and Nest No. 9 with two nestlings, 2-3 days old). In four other nests hatching was in progress (Nos. $3,4,5$ and 7 ), while the remaining nests contained eggs which showed no sign of being about to hatch (Nos. 1, 2, 8 and 10). With the exception of one nest (No. 8), all eggs were hatched during the course of the study.

Attentiveness. - The male and female seemed to share the duties on the nest almost equally. For those of approximately known length, the periods-on during incubation (before start of hatching) lasted on average $35.1 \pm 15.84 \mathrm{~h}$ (range $14-60 \mathrm{~h}, \mathrm{~N}=10$ ). One male sitting on the eggs at the start of the study, continued to incubate for a further $79.4 \mathrm{~h}$ before he was relieved by his mate (Nest No. 2).

For the hatching period the duration of only three complete periods-on is known. Two different males incubated for 19.8 and $25.6 \mathrm{~h}$, respectively, while one female incubated for $24 \mathrm{~h}$.

Considering only the data for the five penguin pairs of known sex, the survey covered the initial 3-8 days of the nestling period. The males 


\section{DECEMBER}
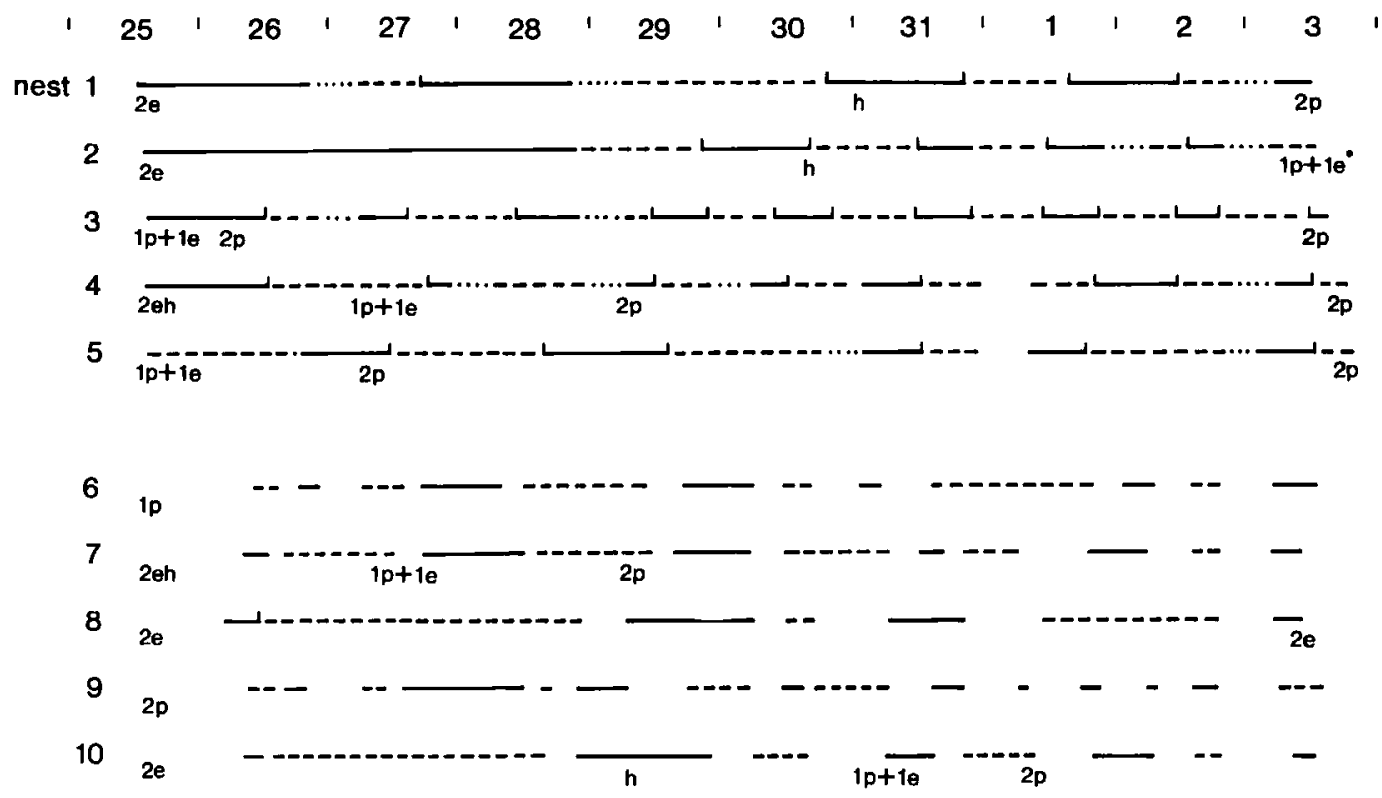

Fig. 2. Division of labour during the breeding season between the male and female of ten different pairs of Chinstrap penguins. The respective mates were distinguished by the breast of one parent being painted yellow. The actual sex of each was known only for pair Nos. 1-5; for these pairs the solid line denotes male, dashed line female. At the start of the survey pair Nos. 3 and 5 each had one egg and one newly-hatched chick, pair No. 6 had only one newly hatched chick, and pair No. 9 had two chicks, about 2-3 days old. e = egg(s), $e^{*}=$ infertile egg, $p=\operatorname{chick}(s), h=$ hatching. Short vertical lines mark the observed relief times. Dotted lines denote intervals of time during which a relief took place, but exact time is unknown.

brooded the young for a mean period of $13.9 \pm 4.33 \mathrm{~h}$ (range $8.1-23.5 \mathrm{~h}, \mathrm{~N}=22$ ), the females for $15.2 \pm 5.83 \mathrm{~h}$ (range $9.1-31.8 \mathrm{~h}, \mathrm{~N}=$ 22). The difference is not significant ( $t$-test, $p>0.40$ ). The mean duration for both sexes combined is $14.8 \pm 5.11 \mathrm{~h}$. This is significantly shorter than the mean duration of the periods-on recorded for the last few days of the incubation period (Mann-Whitney U-test, $p<0.001$ ). The mean length of the periods-on during the hatching period is probably intermediate, as suggested at least by the sparse data for this stage.

Relief time.- During the daytime, a continuous directional movement of penguins was observed in the colony. The numbers of birds walking about and their overall direction of movement showed a diurnal rhythm. In the morning the majority of birds headed for the sea, although numbers declined rapidly. Around noon, some birds were still setting off seawards when others had begun to return, so for a spell about equal numbers of birds were heading in both directions simultaneously on the sea-shore. Interestingly enough, no 'collisions' took place, because the returning birds took a different route from those heading for the sea. The number of birds returning from the sea increased towards the evening, and around sunset there was a compact and coherent mass of birds moving back into the colony.

From this pattern of events one would expect most of the birds present in the morning to be relieved in the afternoon, with a peak in the evening, or during the night. This prediction is partly borne out by the data shown in Table 1 . The anomaly is that quite a number of birds were relieved around noon, in other words at a time of the day when, on the whole, relatively few birds were returning to the colony. I do not know whether some birds returning to the nest in the evening waited until early the following morning before relieving their partner, but probably most of them changed over before midnight. In the calculations above I rather arbitrarily used $2200 \mathrm{hrs}$ as the relief time for both sexes if the exact time was unknown.

Most data in Table 1 are from the early nestling period. In Fig. 3 these data are combined with 
Table 1. Times of day when the two sexes of Chinstrap penguins relieved each other on the nest during the last few days of the incubation period and the initial nestling period (hatching period included), as observed from the time-lapse films.

\begin{tabular}{llllllllllll}
\hline Time of day & $04-06$ & $06-08$ & $08-10$ & $10-12$ & $12-14$ & $14-16$ & $16-18$ & $18-20$ & $20-22$ & $22-24$ & $\begin{array}{c}\text { Night } \\
\text { (unspec) }\end{array}$ \\
\hline Male & - & - & 3 & 5 & 1 & 3 & 3 & 3 & - & - & 9 \\
Female & - & - & - & 8 & 5 & 2 & 1 & 3 & 5 & - & 6 \\
Total & - & - & 3 & 13 & 6 & 5 & 4 & 6 & 5 & - & 15 \\
\hline
\end{tabular}

the actual attentive periods. Again it appears that most change-overs took place either around midday (0900-1300 hrs) or in the evening/night (from about 2100 hrs onwards).

The data in Fig. 3 show no difference between sexes with regard to daily rhythm of attentiveness. Periods-on starting between 0800 and $1300 \mathrm{hrs}$ usually lasted until the following evening or night. Those starting after $1300-1400 \mathrm{hrs,} \mathrm{however,}$ lasted throughout the night until about mid-day the next day, as did those starting in the evening/ night. Irrespective of the starting time, therefore, there was a clear tendency towards adjustment of the duration of the periods-on to change-overs either around mid-day or in the evening/night. Consequently, periods-on which began around mid-day or in the evening/night lasted on the average about $12 \mathrm{~h}$ for both sexes, whereas those starting in the period $1300-1900$ hrs lasted much longer, on the average $21 \mathrm{~h}$.

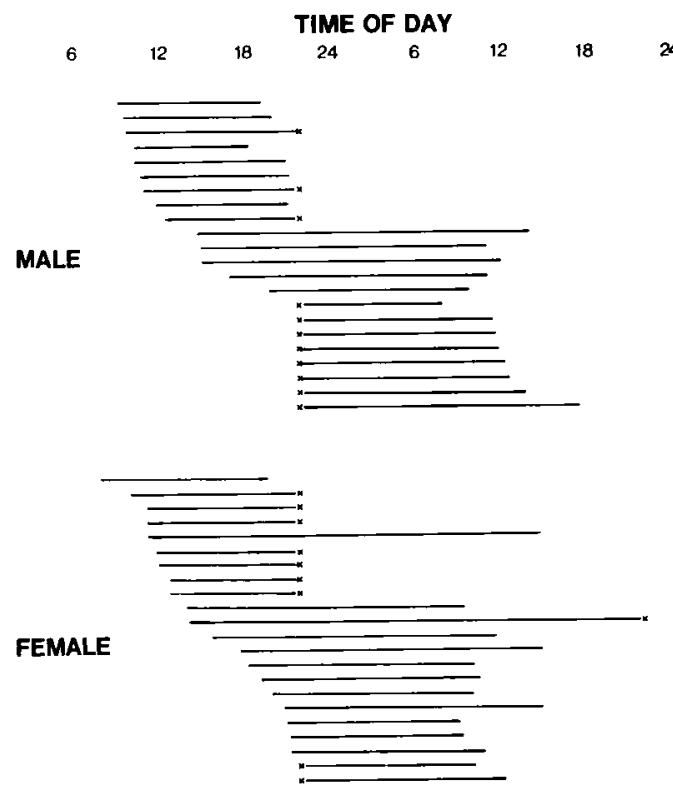

Fig. 3. Brooding periods of adult Chinstrap penguins during the early nestling period. Crosses denote that the change-overs occurred during the night, but the exact time is unknown.
Waiting time before relief. - Immediately upon return of a bird to the nest, an obligatory greeting ceremony took place (mutual display, see Fig. 4a). Relief on the nest could occur within the next minute or so, but there was often a pause of very variable duration. During the incubation and hatching periods, I twice noted that the inattentive bird barely left the vicinity of the nest between two successive periods-on. In one case the male had incubated for more than $32 \mathrm{~h}$ when relieved by its mate. She then spent $18.8 \mathrm{~h}$ on the nest, but during only two of these hours was the male out of sight of the camera.

During the initial nestling period, the male waited, on average, for $18 \pm 16.1 \mathrm{~min}$ (range 3$44 \mathrm{~min}, \mathrm{~N}=12$ ) beside the nest until relief took place. The respective mean waiting time for the female during the same period was $13 \pm 17.0 \mathrm{~min}$ (range $1-67 \mathrm{~min}, \mathrm{~N}=18$ ). The difference is insignificant ( $\mathrm{t}$-test, $\mathrm{p}>0.20$ ).

Reluctance to return to the sea.- As mentioned above, after being relieved, birds sometimes refrained from entering the sea between two successive periods-on during the incubation and hatching periods. But data from these periods are rather sparse. The males remained beside the nest for periods of $56 \mathrm{~min}$ up to at least $12.8 \mathrm{~h}$ before departing $(\mathrm{N}=5)$ and the females for $9 \mathrm{~min}$ up to at least $4 \mathrm{~h}(\mathrm{~N}=4)$.

Even after hatching was completed, the relieved birds seemed to be in no hurry to depart at once, although their reluctance was less pronounced than previously. Furthermore, the duration of delay in departure during the nestling period depended on the particular time of day at which relief occurred. The mean time of delay after reliefs which took place before $1800 \mathrm{hrs}$ was $57 \pm 35.1 \mathrm{~min}$ (range 13-89 (150) $\mathrm{min}, \mathrm{N}=12$ ) for the males, and $35 \pm 24.3 \mathrm{~min}$ (range 0-75 min, $\mathrm{N}=11$ ) for the females. One exceptionally long delay, which lasted at least $7 \mathrm{~h}$ and concerned one male relieved by his mate at $1410 \mathrm{hrs}$, has been omitted from these calculations. This male was 


\section{S. Haftorn}

Table 2. Mean time budget data for four pairs of incubating and brooding Chinstrap penguins (expressed as percentages of total observation time).

\begin{tabular}{|c|c|c|c|c|}
\hline & \multicolumn{2}{|c|}{$\begin{array}{c}\text { Male } \\
\text { Proportion of time spent }\end{array}$} & \multicolumn{2}{|c|}{$\begin{array}{c}\text { Female } \\
\text { Proportion of time spent }\end{array}$} \\
\hline & Prone & Upright & Prone & Upright \\
\hline \multicolumn{5}{|l|}{ Incubation period } \\
\hline Resting and sleeping & 92.21 & 2.99 & 92.65 & 4.76 \\
\hline Agonistic and territorial defence & 0.32 & 0.30 & 0.27 & 0.03 \\
\hline Nest building & 0.23 & 0.34 & 0.06 & 0.06 \\
\hline Preening & 0.02 & 1.64 & - & 0.09 \\
\hline Rotations & - & 0.55 & - & 0.34 \\
\hline Egg-shifting & - & 0.86 & - & 1.34 \\
\hline Mutual displays & - & 0.04 & - & 0.12 \\
\hline Ecstatic displays & - & 0.30 & - & - \\
\hline Unknown & 0.02 & 0.17 & 0.09 & 0.18 \\
\hline Total & 92.80 & 7.19 & 93.07 & 6.92 \\
\hline Observation time (minutes) & \multicolumn{2}{|c|}{5248} & \multicolumn{2}{|c|}{3279} \\
\hline \multicolumn{5}{|l|}{ Hatching period } \\
\hline Resting and sleeping & 85.69 & 8.86 & 83.71 & 9.58 \\
\hline Agonistic and territorial defence & 0.28 & 0.32 & 0.16 & 0.16 \\
\hline Nest building & 0.32 & 0.11 & 0.37 & 0.16 \\
\hline Preening & - & 0.82 & - & 0.75 \\
\hline Rotations & - & 0.82 & - & 0.75 \\
\hline Egg-shifting/touching young & - & 2.21 & - & 4.10 \\
\hline Mutual displays & - & 0.07 & - & 0.05 \\
\hline Ecstatic displays & - & 0.25 & - & 0.21 \\
\hline Unknown & 0.07 & 0.18 & - & - \\
\hline Total & 86.36 & 13.64 & 84.24 & 15.76 \\
\hline Observation time (minutes) & \multicolumn{2}{|c|}{2810} & \multicolumn{2}{|c|}{1878} \\
\hline \multicolumn{5}{|l|}{ Nestling period } \\
\hline Resting and sleeping & 47.59 & 47.69 & 64.65 & 30.59 \\
\hline Agonistic and territorial defence & 0.03 & 0.16 & 0.13 & 0.21 \\
\hline Nest building & 0.03 & 0.16 & 0.01 & 0.23 \\
\hline Preening & - & 0.05 & - & 0.22 \\
\hline Rotations & - & 0.25 & - & 0.59 \\
\hline Touching young & - & 3.36 & - & 3.13 \\
\hline Mutual displays & - & 0.10 & 0.01 & 0.12 \\
\hline Ecstatic displays & - & 0.33 & - & 0.06 \\
\hline Unknown & - & 0.24 & - & 0.04 \\
\hline Total & 47.65 & 52.34 & 64.80 & 35.19 \\
\hline Observation time (minutes) & \multicolumn{2}{|c|}{9147} & \multicolumn{2}{|c|}{8166} \\
\hline
\end{tabular}

Table 3. Proportions of time spent prone and upright by attentive Chinstrap penguins during the last few days of the incubation period, the hatching period, and the initial nestling period ( $\mathrm{N}=$ total observation time in minutes).

\begin{tabular}{|c|c|c|c|c|c|c|}
\hline & \multicolumn{3}{|c|}{$\begin{array}{c}\text { Male } \\
\text { Proportion of time spent }\end{array}$} & \multicolumn{3}{|c|}{$\begin{array}{c}\text { Female } \\
\text { Proportion of time spent }\end{array}$} \\
\hline & Prone & Upright & $\mathbf{N}$ & Prone & Upright & $\mathbf{N}$ \\
\hline Incubation period & 92.8 & 7.2 & 5248 & 93.1 & 6.9 & 3279 \\
\hline Hatching period & 78.0 & 22.0 & 3412 & 83.2 & 16.8 & 2462 \\
\hline Nestling period, Days $1-2$ & 77.1 & 22.9 & 3418 & 80.4 & 19.6 & 2573 \\
\hline Days 3-4 & 53.1 & 46.9 & 2503 & 63.2 & 36.8 & 2601 \\
\hline Days $5-6$ & 5.6 & 94.4 & 1865 & 29.5 & 70.5 & 990 \\
\hline Days $7-8$ & 7.0 & 93.0 & 754 & 4.3 & 95.7 & 419 \\
\hline
\end{tabular}


still beside the nest at $2107 \mathrm{hrs}$. In comparison, the mean minimum delay after reliefs which occurred during the evening (1820-2112 hrs) was $74 \mathrm{~min}$ $(\mathrm{N}=6)$. The exact length of the delay periods in these cases remained unknown because of darkness.

Foraging trips. - During the incubation and hatching periods, the relieved bird was out of sight of the camera, i.e. presumably at sea, for spells which lasted from 17.8 to at least $79.5 \mathrm{~h}$, on average $29.3 \pm 17.03 \mathrm{~h}(\mathrm{~N}=13)$, excluding one record of only $2 \mathrm{~h}$. This was a male which remained close to the nest during the whole period-off lasting $79 \mathrm{~h}$ except for these $2 \mathrm{~h}$.

One female, having incubated $29.1 \mathrm{~h}$ when relieved by the male, spent her time off in the close vicinity of the nest before incubating for another $4.5 \mathrm{~h}$. This would imply that she must have spent altogether $53 \mathrm{~h}$ on land between two consecutive feeding excursions.

During the nestling period the duration of time spent away from the nest by the adults was definitely shorter. The mean time for the males was $8.4 \pm 1.49 \mathrm{~h}$ (range $6.1-10.5 \mathrm{~h}, \mathrm{~N}=8$ ), and for the females $9.4 \pm 1.14$ (range 7.7-11.5 h, $\mathrm{N}=9$ ). These periods, however, were during daylight hours only. For periods including night-time, the mean time away from the nest for males increased to $14.2 \pm 3.76 \mathrm{~h}$ (range $11.5-23.5 \mathrm{~h}, \mathrm{~N}=11$ ) and for females to $15.9 \pm 3.65 \mathrm{~h}$ (range $13.5-22 \mathrm{~h}$, $\mathrm{N}=9$ ). The overall mean time spent away was $11.8 \pm 4.16 \mathrm{~h} \quad(\mathrm{~N}=19)$ by the males and $12.7 \pm 4.28 \mathrm{~h}(\mathrm{~N}=18)$ by the females. This difference between the sexes is insignificant ( $t$-test, $\mathrm{p}>0.80$ ).

Behaviour on the nest.- Only about $5 \%$ of the time otherwise spent in incubating the eggs or brooding the young was devoted to other activities when on the nest, according to the data from the time-lapse films (Table 2). The rest of the time, i.e. about $95 \%$, was spent by the bird in a resting or sleeping incubation posture. Any upright posture, in which the bird was 'looking down' but otherwise apparently inactive, was also included in this category.

Agonistic behaviour or territorial defence was usually aroused by other penguins passing close to the nest. The attentive bird, however, never left the nest during such events.

Nest building, i.e. moving and arranging nest stones with the bill, was carried out by both sexes, both in an upright and in a prone posture. Total time devoted to nest-building by the male progressively declined, but not that by the female. This trend was statistically insignificant, however $\left(\chi^{2}\right.$-test).

Preening movements on the nest were mainly performed when the birds were standing upright.

Rotations on the nest, i.e. changes of the incubating position, have probably not always been properly distinguished from the half-prone resting posture on the time-lapse films, and may therefore be under-represented in the data shown in Table 2. During rotations, the eggs are probably turned and their relative position altered (see Derksen 1977).

Egg-shifting. Sitting upright, the birds turned the eggs from time to time with the bill. This was often combined with rotation on the nest.

Touching young with the bill involved feeding by regurgitation.

Sexual display. The most easily recorded are mutual and ecstatic displays. The mutual display data in Table 2 mainly concern loud mutuals made in connection with nest relief (Fig. 4a). The ecstatic display (Fig. 4b) was exhibited by both males and females, although most often by the former.

Prone versus upright posture. Incubating birds almost entirely adopted the prone posture, in excess of $90 \%$ of the total attentive time by both sexes (Table 3). At the transition to the hatching period the proportion of time spent in prone postures declined slightly, but significantly, relative to time spent in upright postures $\left(\chi^{2}\right.$-test, $p<0.001)$. This applied to both sexes. During the first eight days of the nestling period the proportion of time spent prone declined abruptly from about $77-80 \%$ to only $4-7 \%$ ( $\chi^{2}$-test, $\mathrm{p}<0.001)$.

Hatching period.- The eggs in a clutch of two hatched asynchronously with a maximum interval of 2-3 days (6 nests). The maximum time elapsing between external pipping (star-fracturing) and hatching was in one instance $15 \mathrm{~h}$, in another $28 \mathrm{~h}$.

Body weight and food.- Two newly hatched chicks weighed 72 and $83 \mathrm{~g}$. Two adult males, captured on a nest containing chicks, weighed $4300 \mathrm{~g}$ (stomach empty) and $4900 \mathrm{~g}$ (stomach almost full). Three adult females, likewise with chicks, weighed $4150 \mathrm{~g}$ (empty stomach), $4000 \mathrm{~g}$ 

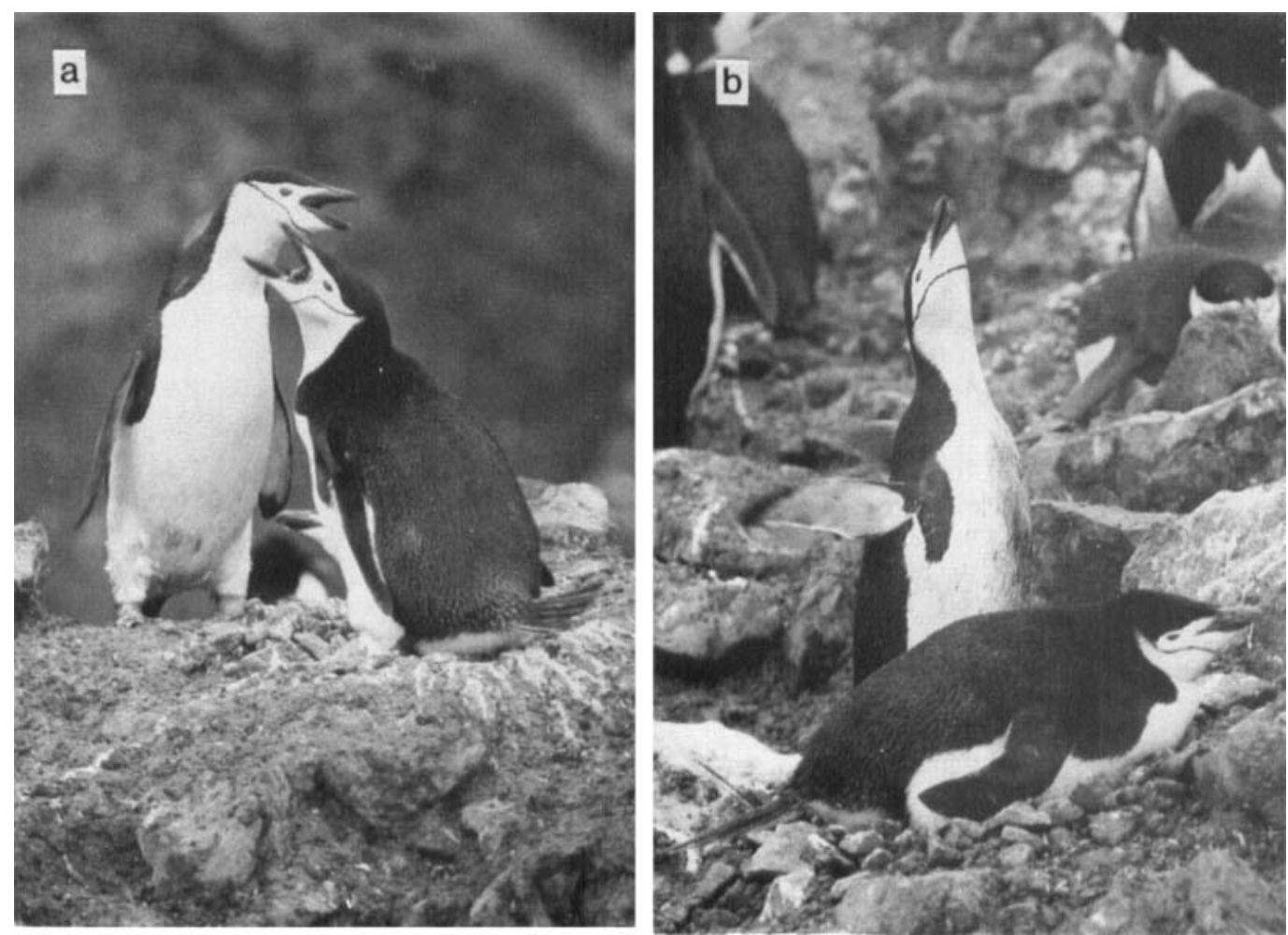

Fig. 4. Sexual display of the Chinstrap penguin. $\mathrm{a}=$ mutual display (greeting ceremony), $\mathrm{b}=$ ecstatic display.

(half-filled stomach) and $4900 \mathrm{~g}$ (stomach full). Seven adults of unknown sex weighed 3950$5300 \mathrm{~g}$. The stomach contents of six adults consisted entirely of krill Euphausia superba (S. Fevolden, pers. comm.).
Egg temperature.- The mean egg temperature recorded for a single-egg clutch (the egg itself being temporarily substituted by the $\mathrm{T}$-egg) was $37.38 \pm 0.52^{\circ} \mathrm{C}$ (range $34.8-38.0^{\circ} \mathrm{C}, \mathrm{N}=189$ ). Egg temperature was taken every second minute,

Table 4. Mean time budget data for three pairs of incubating Macaroni penguins (expressed as percentages of total observation time).

\begin{tabular}{lcccc}
\hline & \multicolumn{2}{c}{$\begin{array}{c}\text { Male } \\
\text { Proportion of time spent } \\
\text { Prone }\end{array}$} & $\begin{array}{c}\text { Femalc } \\
\text { Upright }\end{array}$ & Proportion of time spent \\
Upright
\end{tabular}


from 1000 to $1700 \mathrm{hrs}$. One adult incubated continuously during this period. The mean value of readings taken at quarter-hour intervals during the following evening and night, when its partner was incubating, was $34.45 \pm 2.84^{\circ} \mathrm{C}$ (range 29.0 $38.0^{\circ} \mathrm{C}, \mathrm{N}=49$ ).

\section{The Macaroni penguin}

At the start of the time-lapse recordings on 25 December, the five nests concerned contained one egg each. In one nest (No. 5) the egg was hatched between 31 December and 1 January, whereas the egg in the remaining four nests had still not been hatched by the time the study finished on 3 January (two eggs contained large embryos and two other eggs were infertile).

During the part of the incubation period covered by the survey, i.e. the stage just before hatching, the male took by far the largest share of incubation, no less than $81.8,83.9,94.9$, and $100 \%$, in fact, at four of the nests (Nos. 1-4, Fig. 5).

At nest No. 2 the male incubated without interruption throughout the observation period, his mate never appearing once.

On three nests (Nos. 1, 3, 4) the males were relieved by the females for $1-3$ short spells, lasting $0.9-21.6 \mathrm{~h}$ (mean $10.6 \mathrm{~h}, \mathrm{~N}=7$ ). In general, the males remained beside the nest during these spells, although at nest No. 4 he did once leave the nest for four hours while the female incubated.

Presence or absence of the female at the nest varied greatly among the pairs studied. At nest No. 2 the female, as mentioned above, did not show up at all during the survey. At the other extreme there was the female at nest No. 4, who remained present during the whole period, but incubated for only $5 \%$ of the total observation time. At nests Nos. 1 and 3 the females were absent for most of the time when they were freed from incubating. They returned to the nest 1379 min before relieving the male, and remained beside the nest for a variable length of time, from $1 \mathrm{~min}$ to at least $9 \mathrm{~h}$, after the male had taken over again. Their proportion of the total incubation effort was $18 \%$ and $11 \%$, respectively.

At nest Nos. 5 the female incubated for about $11 \mathrm{~h}$ (in two spells), or $15 \%$ of the observation period from 25 to 28 December. She was away for a total time of at least $23 \mathrm{~h}$ during this period, whereas the male was present at the nest all the time. From the afternoon of 28 December until the survey ended on 3 January, both mates were continuously present at the nest. They frequently took turns at sitting on the nest, but because they were often hidden behind another pair of Macaroni penguins, it was impossible to monitor their time-schedules thoroughly from the timelapse films. The single egg was hatched at sometime between $0542 \mathrm{hrs}$ on 31 December and 1015 hrs on 1 January.

Behaviour on the nest.- With the exception of egg-shifting and rotations on the nest, the incubating birds were fairly inactive (Table 4). The relatively high frequency of preening movements recorded for the males is mainly due to one particular individual of the three studied (the proportion of preening by this bird was $3.2 \%$ ).

Because the females took only a minor part in incubation during the survey period, the data for their activities while sitting on the nest are sparse. It is noteworthy, however, that the ratio between prone and upright incubation postures of the females differed significantly from that of the males $\left(\chi^{2}\right.$-test, $\left.p<0.001\right)$. The males adopted an upright or semi-upright position to a much higher degree. This difference was found for both the nests in which the female assisted in incubation.

DECEMBER

JANUARY

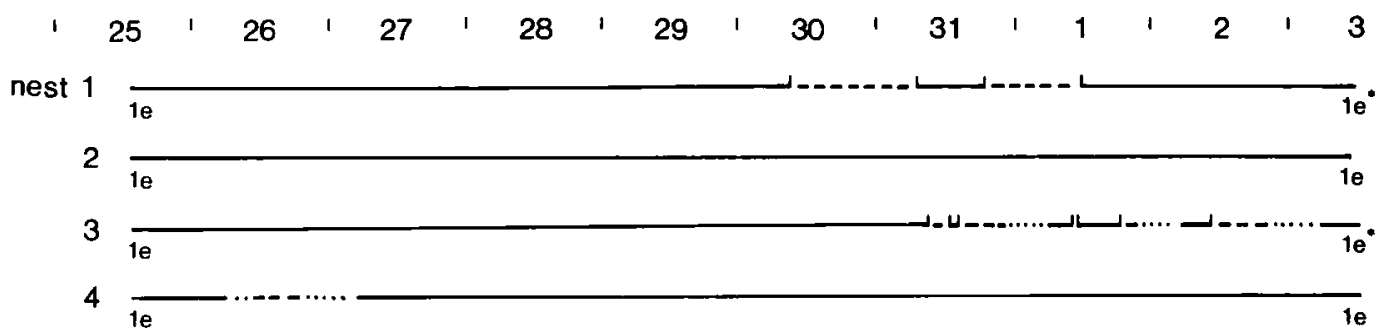

Fig. 5. Division of labour during the breeding season between the males and females of four different pairs of Macaroni penguins The solid lines denote activity by the male and the dashed lines that of the female. Each nest contained only a single egg during the entire observation period. For further details see the text to Fig. 2. 
Egg temperature.- At one nest with a single egg, the egg temperature was measured every second minute for about $5 \mathrm{~h}$ from $0600 \mathrm{hrs}$ in the morning, after the egg had been temporarily substituted by the T-egg. The mean egg temperature was $36.65 \pm 1.76^{\circ} \mathrm{C}$ (range $31.0-37.8^{\circ} \mathrm{C}, \mathrm{N}=159$ ) During a period of about $40 \mathrm{~min}$ the egg temperature was consistently lower $\left(31-34^{\circ} \mathrm{C}\right)$ than it was during the rest of the recording period. The cause was probably that the incubating bird had turned the egg dislodging the temperature probe from its original position at the top. When this period of low temperatures was excluded, the mean egg temperature increased to 37.27 $\pm 0.59^{\circ} \mathrm{C}(\mathrm{N}=139)$.

Body weight.- The mean weight of nine adult males captured in the colony on 30 December and 3 January was $5119 \pm 501$ g (range $4200-5900 \mathrm{~g}$ ). They all had empty stomachs. Surprisingly enough, this was also true of one male (weight $4700 \mathrm{~g}$ ) caught on its nest (containing one egg) at 1845 hrs immediately after it had returned from the sea.

Four of the five birds observed by time-lapse photography, and caught on their nests on 3 January, had gone without food from at least 25 December, i.e. for at least 12-13 days, and yet were still in good condition, with considerable fat reserves (body weights of $5200-5900 \mathrm{~g}$ ). The fifth male was once absent from the nest for $4 \mathrm{~h}$ during the above period, but probably did not enter the sea. He was also fat and weighed $5550 \mathrm{~g}$.

\section{Discussion}

According to the present data on the Chinstrap penguin, parental duties at the nest during the days just before and after hatching are shared about equally between the male and female. Including the hatching period, the male incubated on average for $58 \%$ of the time, and during the early days of the nestling period he brooded for $48 \%$.

For this same species, the incubation spells of known length $(\mathrm{N}=10)$ lasted on average for only $35 \mathrm{~h}$, or 1.46 days, with a range of $14-60 \mathrm{~h}$. These spells are significantly shorter (t-test, $p<0.001$ ) than those recorded for the colony on Signy Island in the South Orkney Islands by Conroy et al. (1975a). They recorded a mean value of 2.84 days, with a range of 1-9 days, although the first (long) spell of incubation by the female once the clutch had been completed was excluded from this calculation. Apart from this initial span, Conroy et al. (1975a) found no difference in the length of the incubation spans as hatching time approached, or after the chicks had appeared.

However, Lishman (1985) found that after four long shifts, each lasting 5-10 days (the first one by the female), there was a 5-6 day period with irregular short shifts prior to hatching. These short shifts were less than three days in duration. My findings covering the last part of the incubation period are therefore consistent with those of Lishman.

After hatching, the duration of the attentive periods of the Chinstraps on Bouvetøya decreased significantly, the mean brooding period lasting only $14.8 \mathrm{~h}$.

Conroy et al. (1975b) suggested that the Chinstraps on Elephant Island in the South Shetland Islands had a 12 or $24 \mathrm{~h}$ brooding period, with the majority of change-overs occurring around midday or during the night. The data from the early nestling period on Bouvetøya indicate that the basic brooding period is $12 \mathrm{~h}$, with change-overs mostly around mid-day or in the evening/night as on Elephant Island. Deviations from the $12 \mathrm{~h}$ rhythm seem to be caused by change-overs taking place at times outside the main schedule. Thus, birds which started a period-on in the afternoon tended to brood throughout the night until around noon the next day. Consequently their brooding periods exeeded $12 \mathrm{~h}$ and approached $24 \mathrm{~h}$ (Fig. 3).

When not incubating, the Chinstrap penguins on Bouvet $\varnothing y$ a spent their time partly sitting beside the nest and partly being away at sea. On average, the periods spent away from the nest lasted for $29.3 \mathrm{~h}$ and were significantly longer than those recorded after hatching. The mean time spent away from the nest during the initial nestling period was only $8.4 \mathrm{~h}$ for the males and $9.4 \mathrm{~h}$ for the females (difference not significant). The short time that either parent spent at sea clearly indicates that they must have been feeding close inshore.

Also for the crested penguins of the genus Eudyptes, to which the Macaroni penguin belongs, the incubation duties are fairly equally shared between the sexes. The females of both the Macaroni and Rockhopper E. chrysocome usually take the first long spell on the eggs. This lasts some 13-18 days (Warham 1975), after which the last stage of the incubation period is left to 
the male. The female normally returns to the nest either before or soon after the chick has been hatched and feeds the chick frequently during the two or three days that both parents remain together at the nest (Downes et al. 1959; Warham 1975). Thereafter the female is said to disappear during the day-time, leaving the male in sole charge of the nest. This is termed the guard stage, during which the male fasts for 3-4 weeks on end. Feeding of the chick during this period is entirely the female's responsibility, and she visits the nest almost daily for this purpose. According to Warham (1975) this procedure is common to all species within the genus Eudyptes so far studied.

By and large my data agree with the description of events given above. The time at which the Macaroni female returned to its nest, prior to hatching, seemed to vary considerably among pairs, however. In one case, for example, the female attended the incubating male during the whole of the observation period ( 10 days), at the end of which the single egg in the nest contained an embryo ready to be hatched. Although continuously present beside the nest, she only relieved the male for two short periods, accounting for $5 \%$ of the total observation time. In two other nests, also with one egg each, the females were present beside their nests for 20 and $23 \%$ of the total observation time (10 days), and incubated for 11 and $18 \%$ of the time, respectively (Fig. 5). The males usually remained beside the nest during the females' short spells of incubation.

During incubation, both sexes of the Chinstrap penguin generally adopted a prone position, on average for $93 \%$ of the time. This finding is consistent with that made for the congeneric Adelie penguin, which, from laying to hatching, adopted prone positions for $87-95 \%$ of the time (Derksen 1977).

By comparison, the Macaroni penguin adopted prone positions significantly less often. The difference was especially marked with regard to the males (prone positions 57\%), but the females, too, incubated prone significantly less than the Chinstrap females did (87 and 93\%, respectively; $\chi^{2}$-test, $\left.\mathrm{p}<0.001\right)$.

The intensity, or efficiency, of incubation by the Adelie penguin is considered to be reflected by the amount of time an incubating bird spends in the prone rather than the upright position, because in the latter the eggs may only be partially covered by the brood patch (Derksen 1977). Yet the male Macaroni, which is about the same size as the male Adelie penguin, adopted an upright position almost as frequently as a prone position (43\% and $57 \%$ of total time, respectively). A reasonable explanation for this discrepancy is that the Macaroni penguin usually incubates only a single egg, compared to the Adelie and Chinstrap penguins which usually have two eggs in the nest. Having only one egg, the Macaroni evidently finds no difficulty in maintaining it at the optimal temperature even when sitting upright.

With the diminished need for a firm covering of the nest contents after hatching, the frequency with which the Chinstrap adopts an upright posture on the nest increases rapidly. In the present study the parent birds spent more than $90 \%$ of the total brooding time upright as early as the fifth-sixth day of the nestling period. In fact, a decrease in the intensity of incubation, as expressed by an increase in time spent in upright postures, was already evident by the time of the transition from the incubation period to the hatching period ( $\chi^{2}$-test, $p<0.001$, for both sexes). The same clear trend was also observed in the Adelie penguin (Derksen 1977).

Up to a few years ago, the temperature of penguin eggs during incubation was assumed to be lower than is generally the case in birds, because the thermal conductance through the integuments is reduced and their body temperatures at rest are about $2^{\circ} \mathrm{C}$ below the average for species in other avian orders, excepting Procellariiformes (cf. Burger \& Williams 1979; referring to Kooyman et al. 1976 and McNab 1966). However, the mean egg temperatures measured telemetrically during the second half of the incubation period in four different penguin species, namely the Adelie, Rockhopper, Gentoo Pygoscelis papua and Jackass Spheniscus demersus, have recently been shown to range from $32.9^{\circ} \mathrm{C}$ to $36.0^{\circ} \mathrm{C}$ (Derksen 1977; Burger \& Williams 1979). As pointed out by Burger \& Williams (1979), these values fall within, or are only just below, the range of the mean egg temperatures $\left(34-39^{\circ} \mathrm{C}\right)$ recorded for 24 species of birds belonging to nine different orders, quoted by Drent (1975). My present data for the egg temperature of two other penguin species, the Chinstrap and Macaroni penguins, are consistent with or even higher than the values mentioned above, averaging $37.4^{\circ} \mathrm{C}$ for both species. This value refers to the temperature at the top of the egg, however (just below the egg-shell, i.e. close to the heated brood patch). Other workers have inserted the 
sensitive probe into the air-space of the egg (Burger \& Williams 1979), or perhaps even into the centre of the egg, where the temperature, according to the data for other bird species, is definitely lower than at the top. When the Tegg which I used was repeatedly turned by the incubating bird, as indicated by an increased variation in egg temperature with time, the recorded mean egg temperature decreased, falling to $34.4^{\circ} \mathrm{C}$ during one night's observation period for the Chinstrap penguin.

When incubating, the males and females of both species studied spent most of their time resting or sleeping in a prone or upright posture. According to the time-lapse films the incubating birds spent more than $90 \%$ of their time inactive. Egg-shifting, rotations on the nest, and preening movements together accounted for only about 2$3 \%$ of the time spent incubating.

Agonistic behaviour and territorial defence by both species were observed much more seldom than by Derksen (1977) in the case of the Adelie penguin. During the late incubation period $26.7 \%$ of total time was devoted to such activities by this species, compared to only $0.9 \%$ by the Chinstrap and $0.1 \%$ by the Macaroni penguins. Such activities were in the Adelie frequently aroused by birds searching for nest stones nearby, whereas birds passing by on their way to or from the sea seemed to be the main releasing factor in the case of the last two species.

The mutual displays noted were usually performed in connection with nest reliefs.

Ecstatic displays were sporadically observed during the incubation, hatching and nestling periods. Frequently, several birds took part in the performance each time. When one bird started up, either by stretching its neck vertically (Chinstrap) or by waving its head (Macaroni), and then screaming loudly, conspecifics nesting nearby were stimulated to behave similarly, the effect spreading infectiously to other parts of the colony. The result was an ever-increasing chorus of screams, which carried for several hundred metres. This type of social behaviour is evidently common to several species of penguins (for the Adelie penguin, cf. Sladen 1958 and Spurr 1975). To the best of my knowledge this was first noted, for the Chinstrap, by Riiser-Larsen (1958) during his short visit to Larsøya, Bouvetøya, in 1929, and described anecdotally in his memoirs.

This ecstatic vocalization is probably individually distinctive, and seems to be 'a declaration of self and territory' (Ainley 1975 about the Adelie penguin). According to the evidence of the time-lapse films, this display was usually performed by birds when alone at the nest site. Although usually recorded for the males, it was also made at times by female Chinstraps.

On the time-lapse films nest-building may at times have been confused with other activities. At all events, nest-building by birds sitting in the nest, involving the arrangement of small stones, accounted for only a small proportion of the total observation time. The particular member of a pair which did not happen to be in charge of the nest was, however, frequently to be seen walking about in the vicinity of the nest in search of appropriately-sized stones, which it then carried one by one in its bill to the nest.

All the adult Chinstraps investigated had fed only on krill Euphausia superba, which occurred abundantly in the sea around Bouvetøya during our stay. This lends further support to previous findings that krill is a very important constituent of the diet of the Chinstrap penguin (cf. Croxall $\&$ Furse 1980; Volkman et al. 1980).

Acknowledgements. - I am grateful to one unknown referee for valuable comments on the manuscript, to $P$. A. Tallantire for improving the English, and to I. Harder for typing the manuscript.

\section{References}

Ainley, D. G. 1975: Displays of Adélic penguins: a reinterpretation. Pp. 503-534 in Stonehouse, B. (ed.): The Biology of Penguins. Macmillan, London.

Burger, A. E. \& Williams, A. J. 1979: Egg temperatures of the Rockhopper Penguin and some other penguins. $A u k 96,100$ 105.

Conroy, J. W. H., Darling, O. H. S. \& Smith, H. G. 1975a: The annual cycle of the Chinstrap penguin Pygoscelis antarctica on Signy Island, South Orkney Islands. Pp. 353-362 in Stonehouse, B. (ed.): The Biology of Penguins. Macmillan, London.

Conroy, J. W. H., White, M. G., Furse, J. R. \& Bruce, G. 1975b: Observations on the breeding biology of the Chinstrap Penguin, Pygoscelis antarctica, at Elephant Island, South Shetland Islands. Br. Antarct. Surv. Bull. No. 40, 23-32

Croxall, J. P. \& Furse, J. R. 1980: Food of Chinstrap Penguins Pygoscelis antarctica and Macaroni Penguins Eudyptes chry. solophus at Elephant Island group, South Shetland Islands. lbis 122, 237-245.

Derksen, D. V. 1977: A quantitative analysis of the incubation behaviour of the Adélie Penguin. Auk 94, 552-566.

Downes, M. C., Ealey, E. H. M., Gwynn, A. M. \& Young, P. S. 1959: The birds of Heard Island. Austr. Nat. Antarct. Res. Exped. Rep., ser. B, no. 1, 135 pp. 
Drent, R. 1975: Incubation. Pp. 333-420 in Farner, D. S, \& King, J. R. (eds.): Avian Biology, Vol. V. Academic Press, New York.

Haftorn, S., Sømme, L. \& Gray, J. S. 1981: A census of penguins and seals on Bouvetøya. Nor. Polarinst. Skr. 175 , 29-35.

Kooyman, G. L., Gentry, R. L., Bergman, W. P. \& Hammel, H. T. 1976: Heat loss in penguins during immersion and compression. Comp. Biochem. Physiol. 54, 75-80.

Lishman, G. S. 1985: The comparative breeding biology of Adélie and Chinstrap Penguins Pygoscelis adeliae and $P$. antarctica at Signy Island, South Orkney Islands. Ibis 127, 84-99.

McNab, B. K. 1966: An analysis of the body temperatures of birds. Condor $68,47-55$.
Riiser-Larsen, Hj. 1958: Femti dr for Kongen. Gyldendal Norsk Forlag, Oslo, $271 \mathrm{pp}$.

Sladen, W. J. L. 1958: The pygoscelid penguins. I. Methods of study. II. The Adélie penguin Pygoscelis adeliae Hombron and Jaquinot. Sci. Rep. Falkld. Isl. Depend. Surv. 17, 1-97. Spurr, E. B. 1975: Communication in the Adélie penguin. Pp. 449-501 in Stonehouse, B. (ed.): The Biology of Penguins. Macmillan, London.

Volkman, N. J., Presler, P. \& Trivelpiece, W. 1980: Diets of pygoscelid penguins at King George Island, Antarctica. Condor 82, 373-378.

Warham, J. 1975: The crested penguins. Pp. 189-269 in Stonehouse, B. (ed.): The Biology of Penguins. Macmillan, London. 